\title{
Oral submucous fibrosis a disease with malignant potential - Report of two Cases
}

\author{
Siddharth Pundir ${ }^{1}$, Susmita Saxena ${ }^{1}$, Pooja Aggrawal ${ }^{1}$ \\ ${ }^{1}$ Departament of Oral and Maxillofacial Pathology. Dental College, Meerut (U.P) India.
}

Correspondence:

House NO: 8 Sector-11 Shastri- Nagar,

Meerut (U.P) India

Pincode- 250004

sidpundir2002@yahoo.co.in

\begin{abstract}
Oral submucous fibrosis (OSF) is a high risk precancerous condition characterized by changes in the connective tissue fibers of the lamina propria and deeper parts leading to stiffness of the mucosa and restricted mouth opening. Patients with severe cases have distinct difficulties in chewing, swallowing and speaking. It predominantly occurs in Indians and other population of the Indian subcontinent with certain oral habits. In patients with submucous fibrosis, the oral epithelium becomes atrophic and thereby becomes more vulnerable to carcinogens. It is now accepted that chewing areca is the most important aetiological factor for developing OSF. The atrophic epithelium shows first an intercellular edema and later epithelial atypia associated with moderate epithelial hyperplasia. From then on, carcinoma may develop any time. It is suggested that submucous fibrosis should be regarded as a condition that causes predisposition to the development of oral cancer. Here we are presenting two cases of oral submucous fibrosis showing malignant potential and development of oral squamous cell carcinoma.
\end{abstract}

Key words: Oral sub mucous fibrosis, areca nut, malignant transformation. 


\section{Introduction}

Oral submucous fibrosis (OSF) is a high risk precancerous condition characterized by changes in the connective tissue fibers of the lamina propria and deeper parts leading to stiffness of the mucosa and restricted mouth opening (1).

Although OSF was first described by Schwartz in a series of Indian women living in East Africa there are descriptions of a similar condition occurring in betel chewers in early texts dating back to 1908.(2) Sub mucous fibrosis is an oral condition described by Joshi in 1953 (3). It has been reported mainly from India, but has also been diagnosed in Srilanka, Malaysia, Nepal, South Vietnam, and Thailand (4).

The possible precancerous nature of submucous fibrosis was first mentioned by Paymaster in 1956, who described the development of slow-growing squamous cell carcinoma in one third of the cases with submucous fibrosis (5).

The strongest risk factor for OSF is the chewing of betel quid containing areca nut. OSF is seen most frequently in communities resident in the Indian sub-continent and has a reported incidence of between 0.2-1.2 percent of the urban population attending dental clinics. The condition predominantly affects women with a female: male ratio of 3:1 and characteristically first presents in adulthood between the ages of 45-54 years (6). The potentially malignant nature of this condition has been well documented. A malignant transformation rate of $4.5 \%$ to $7.6 \%$ was found( 7). The present case reports appraise the malignant potential of oral sub mucous fibrosis.

\section{Case Report}

\section{Case Report1}

A 44 year old male patient reported to the Department of Oral Pathology \& Microbiology, Subharti Dental College, Meerut, with a complaint of recurrent oral ulceration and burning sensation affecting the oral mucosa, associated with difficulty in opening the mouth since 5 years. The patient had got his tooth 47 extracted, about one month back and since then the socket had not healed. Past medical history revealed that the patient was on anti- depressants for the past 3 years. History also revealed that the patient had a habit of chewing dried areca nut powder about 5-6 packets per day since 20 years. Intraoral examination was problematic as it was difficult to retract the patient's fibrotic cheeks. The mouth opening was restricted and interincisal distance was about $16 \mathrm{~mm}$. The buccal mucosa showed blanched and slightly opaque mucosa with presence of thick fibrotic bands which were palpable bilaterally and running in vertical direction extending to the retro molar area. The uvula was fibrotic, deformed and the tongue was completely devoid of papillae. When the patient was asked to blow out air with closed lips, the usual puffed-cheek appearance was not seen, suggesting loss of cheek elasticity.

A diagnosis of OSF at a moderately advanced stage was made based on the characteristic oral features: generalized blanching of mucosa, extensive fibrosis and limited mouth opening. In addition to the above changes, an ulcero-proliferative growth (measuring about $3 \times 2 \mathrm{~cm}$ ) was present on the right buccal mucosa extending from the corner of mouth to the molar area showing irregular and indurated margins. It was firm in consistency and fixed to underlying tissue. The sub-mandibular and jugulodigastric lymph nodes were palpable. (Fig .1).

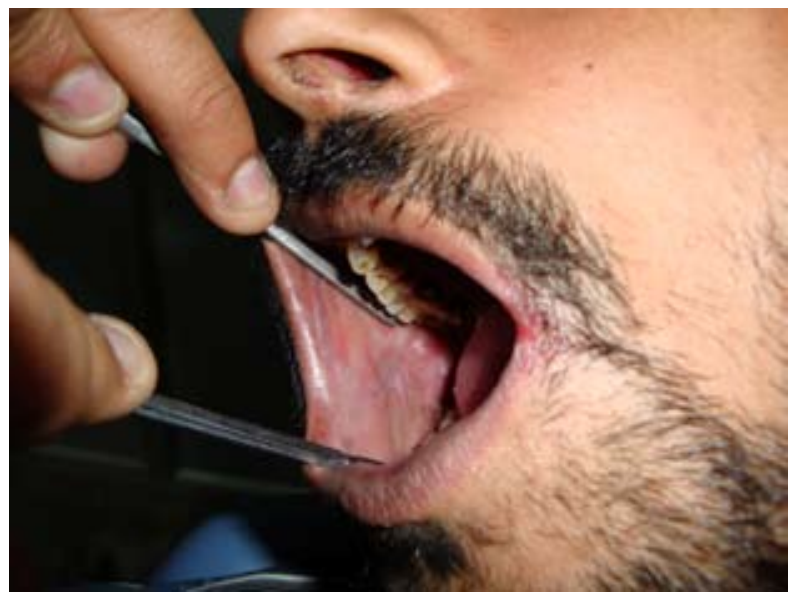

Fig. 1.

Based on the clinical findings, a provisional diagnosis of oral submucous fibrosis was made. The growth was clinically diagnosed as papilloma, verrucous carcinoma, or squamous cell carcinoma.

Case Report2

A 45-year-old male patient reported to the Department of Oral Pathology and Microbiology, Subharti Dental College, Meerut with discomfort and a burning sensation affecting the oral mucosa, particularly when eating spicy food associated with difficulty in opening his mouth since 4-5 months.

Intra oral examination revealed that the mouth opening was limited; interincisal distance was about $23 \mathrm{~mm}$. The buccal mucosa and the lower lip region showed blanched and slightly opaque mucosa, fibrous bands running in vertical direction extending to the retromolar area and also revealed a papillary growth at the right commissural mucosa of the mouth. This papillary lesion was $1 \mathrm{~cm} \mathrm{x}$ $1 \mathrm{~cm}$ in size, well demarcated, firm in consistency with a corrugated surface. (Fig.2.)

History revealed that the patient had a habit of chewing flavored Pan masala in the range of 7-8 packets per day and alcohol consumption of approximately $180 \mathrm{ml} /$ day since 15 years.

The incisional biopsy was done for both the cases and submitted for histopathological examination. Microscopically H\&E stained sections of both the received spe- 


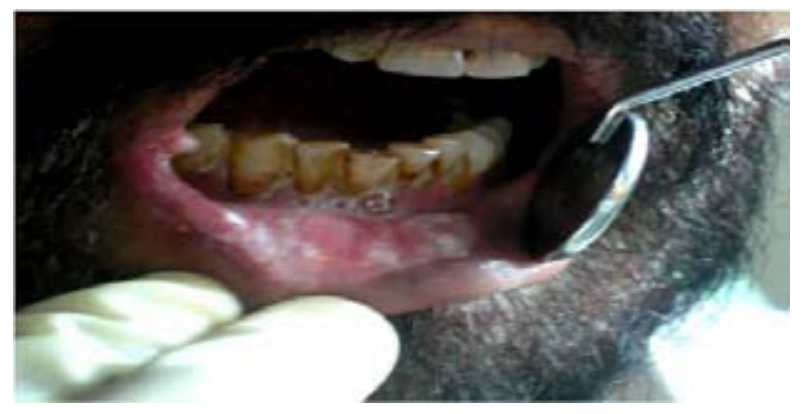

Fig. 2.

cimens showed parakeratinized, hypertrophic stratified squamous epithelium adjacent to dysplastic epithelium invading into the underlying connective tissue with evidence of keratin pearl formation. Dysplastic epithelial islands and proliferating cords with keratin pearl formation were seen within the connective tissue. Intense chronic inflammatory cell infiltration was seen around the invading epithelial islands. Based on the microscopic appearance of both (case report 1 and case report 2) both the lesions were diagnosed as well-differentiated squamous cell carcinoma. (Fig .3, 4).

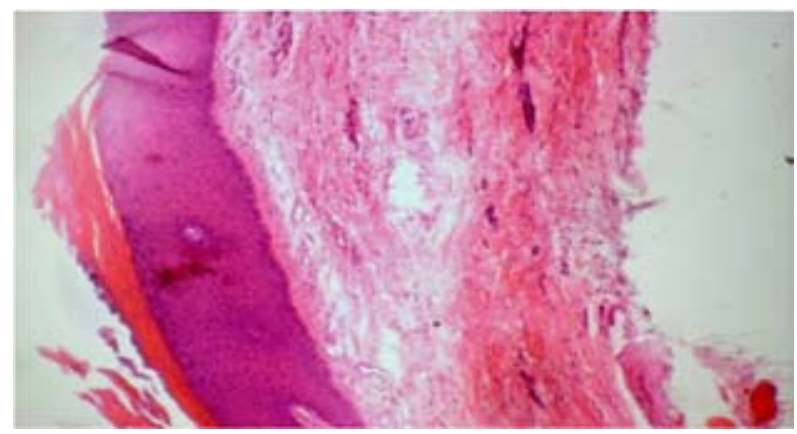

Fig. 3.

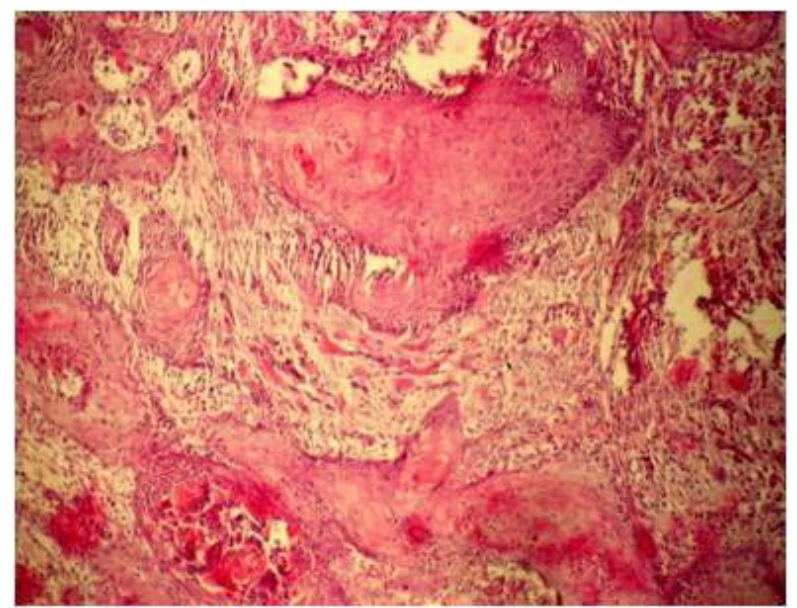

Fig. 4.

\section{Discussion}

OSF is a pre-malignant condition, which has been described in detail in Asians or Asians settled in other countries. Describing the condition in five Indian women in
Kenya, Schwartz called it 'atrophia idiopathica mucosae oris'. Later Joshi redesignated the condition as oral submucous fibrosis, implying predominantly its histologic nature $(2,3,8)$.

Various etiological factors have been suggested for OSF, which include local irritant such as capsaicin, pungent and spicy food and areca nut use (9). In addition to local factors, systemic factors have also been suggested to play a role in the development of OSF. These include anaemia, chronic iron and vitamin B deficiency and genetic pre-disposition (10). Chewing areca nut in its various forms is widely prevalent in the Indian subcontinent, giving rise to increased prevalence of oral sub mucous fibrosis, from an estimated 250,000 cases in 1980 to an estimated 5 million people in 2002 (11).

This is a chronic disorder characterized by fibrosis of the lining mucosa of the upper digestive tract involving the oral cavity, oro- and hypo pharynx and the upper third of the oesophagus.

The fibrosis involves the lamina propria and the sub mucosa and may often extend into the underlying musculature resulting in the deposition of dense fibrous bands, which give rise to the limited mouth opening which is a hallmark of this disorder.

Diagnosis of OSF is usually based on the clinical signs and symptoms, which include; oral ulceration, burning sensation (particularly with spicy foods), paleness of the oral mucosa, and occasional Leukoplakia. The most characteristic feature is the marked vertical fibrous ridge formation within the cheeks, and board like stiffness of the buccal mucosa (11). The fibrosis in the soft tissue leads to trismus, difficulty in eating, and even dysphagia as reported in our cases also.

The potentially malignant nature of this condition has been well documented. A malignant transformation rate of $7.6 \%$ over a period of 10 years was described in an Indian cohort and the relative risk for malignant transformation may be as high as 397.3 (12) .

Much of the evidence-implicating areca has been derived from epidemiological data arising largely from India, Pakistan and South Africa. Many observational studies on OSF patients have recorded a high frequency of the areca chewing habit in the OSF subjects (close to $100 \%$ ) compared to that of the general population (13) . OSF does not regress spontaneously or on cessation of areca nut chewing. Once the disease is present, it either persists or becomes more severe with involvement of additional areas of oral mucosa (14).OSF is strongly associated with a risk of oral cancer, although the biology underlying this association is still unresolved.

OSF may cause atrophy in the epithelium, increasing carcinogen penetration. Studies suggest that dysplasia is seen in about $25 \%$ of biopsied OSF cases and the rate of transformation to malignancy varies from $3 \%$ to $19 \%$ areas of the oral mucosa (13). 
The cases reported here had history of chewing arecanut (case report 1) and Pan masala (case report 2) that contains areca along with other harmful ingredients' which had led to the development of oral submucous fibrosis due to the presence of various components, including biologically active alkaloids, arecoline, arecaidine, arecolidine, guvacoline, guvacine, flavonoids (tannins and catechins) and copper. History revealed that the patients had not received any treatment for the same and had ulcero proliferative growth confirmed as well differentiated squamous cell carcinoma.

The role of areca products in causing oral fibrosis and malignancy and possibly contributing to other diseases has raised important public health issues. These products are inadequately labelled. There are no health warning labels and no restrictions on its sale to children or consumption in public places(15).

Based on the findings in these case reports, it seems reasonable to suggest that sub mucous fibrosis should be regarded as a condition that predisposes to the development of oral cancer.

\section{References}

1. Hazarey VK, Erlewad DM, Mundhe KA, Ughade SN. Oral submucous fibrosis: study of 1000 cases from central India. J Oral Pathol Med. 2007; 36:12-7.

2. Isaac U, Issac JS, Ahmed Khoso N. Histopathologic features of oral submucous fibrosis: a study of 35 biopsy specimens. Oral Surg Oral Med Oral Pathol Oral Radiol Endod.2008: 106: 556-560.

3. Dayal PK, Joshi HN, Dayal JP. Concomitant occurrence of oral submucous fibrosis, pemphigus and squamous cell carcinoma. Indian $\mathrm{J}$ Pathol Microbiol.1988; 31:334-7.

4. Pindborg JJ, Mehta FS, Gupta PC, Daftary DK. Prevalence of oral submucous fibrosis among 50,915 Indian villagers. Br J Cancer. 1968; 22:646-54.

5. Paymaster JC. Cancer of the buccal mucosa; a clinical study of 650 cases in Indian patients. Cancer. 1956; 9:431-5.

6. Jayanthi V, Probert CS, Sher KS, Mayberry JF. Oral submucosal fibrosis--a preventable disease. Gut. 1992; 33:4-6.

7. Ahmad MS, Ali SA, Ali AS, Chaubey KK. Epidemiological and etiological study of oral submucous fibrosis among gutkha chewers of Patna, Bihar, India. J Indian Soc Pedod Prev Dent. 2006; 24:84-9.

8. Sirsat S M, Khanolkar VR. Sub mucous fibrosis of the palate in dietPre conditioned Wister rats. Induction by local painting of capsaicin-an optical and electron microscopic study. Arch Pathol 1960; 70:171-9.

9. Pillai R, Balaram P, Reddiar KS. Pathogenesis of oral submucous fibrosis. Relationship to risk factors associated with oral cancer. Cancer. 1992; 69:2011-20.

10. Canniff JP, Harvey W, Harris M. Oral submucous fibrosis: its pathogenesis and management. Br Dent J. 1986; 160:429-34.

11. Hayes PA. Oral submucous fibrosis in a 4-year-old girl. Oral Surg Oral Med Oral Pathol. 1985; 59:475-8.

12. Gupta PC, Nandakumar A. Oral cancer scene in India. Oral Dis. $1999 ; 5: 1-2$

13. Murti PR, Bhonsle RB, Pindborg JJ, Daftary DK, Gupta PC, Mehta FS. Malignant transformation rate in oral submucous fibrosis over a 17-year period. Community Dent Oral Epidemiol.1985; 13:340-1. 14. Nair U, Bartsch H, Nair J. Alert for an epidemic of oral cancer due to use of the betel quid substitutes gutkha and pan masala: a review of agents and causative mechanisms. Mutagenesis. 2004; 19:251-62.

15. Trivedy CR, Craig G, Warnakulasuriya S. The oral health consequences of chewing areca nut. Addict Biol. 2002; 7:115-25. 